\title{
Yerel Kalkınmada Teknopark Modeli: Emilia-Romagna (Ittalya) ve Shannon (İrlanda) Bölgeleri Örnekleri
}

\section{The Technopark Model in Local Development: Emilia-Romagna (Italy) and Shannon (Ireland) Regions Samples}

\author{
Dr. Fatih ÇELIK $(\mathrm{iD})$
}

\begin{abstract}
$\ddot{\mathbf{O} z}$
Teknopark, bir üniversite veya araştırma kurumunun öncülüğünde üretilen bilginin ticarileştirilmesini amaçlayan bir kurumdur. Teknoparklar, girişimcilere mali ve teknik destek vermektedir. Bilim parkl, yenilik merkezi gibi adlarla da anılmaktadır. Dünyanın ilk teknoparkı, ABD’nin Stanford Üniversitesi bünyesinde 1952 yılında kurulan Stanford Araştırma Parkı'dır (Silikon Vadisi). Yerel kalkınmada yenilikleri teşvik etmek için teknopark kurulması, literatürde "Teknopark Modeli” olarak adlandırılmış̧ır. Çalışmanın amacı, yerel kalkınmada teknopark modelini İtalya'nın Emilia-Romagna ve İrlanda'nın Shannon bölgeleri örnekleri üzerinden analiz etmektir. Bu çerçevede Emilia-Romagna bölgesinin kalkınma ajansı ERVET ile Shannon bölgesinin kalkınma ajansı SD öncülüğünde ekonomik kalkınmayı hızlandırmak üzere kurulan teknoparklar, kuruluş ve gelişme süreçleri ile ortaya konmuştur. Konu, nitel araştırma yöntemlerinden doküman analizi tekniği ile ele alınmıştır. Yapılan analiz ile şu sonuçlara ulaşılmıştır: a) Teknoparklar, yerel kalkınmaya üretim, istihdam, Ar-Ge, yenilik gibi yönlerden katkıda bulunmuştur. b) Teknoparklar ağ üzerinden birbirine bağlanmak suretiyle Sektörel Yenilik Sistemi ve Bölgesel Yenilik Sistemi kurulmuştur.
\end{abstract}

Anahtar Kelimeler: Yerel kalkınma, teknopark modeli, bölgesel yenilik sistemi, Bölgesel Kalkınma Ajansı, Emilia-Romagna bölgesi, Shannon bölgesi

Makale Türü: Araştırma

\begin{abstract}
Technopark is an institution aiming at the commercialization of the information produced under the leadership of a university or research institution. Technoparks provide financial and technical support to entrepreneurs. It is also named as the innovation center, the science park. The world's first technopark is the Stanford Research Park (Silicon Valley), founded in 1952 in the United States under Stanford University. Establishment of technoparks to encourage innovation in local development is called "Technopark Model" in the literature. The aim of the study is to analyze the technopark model in local development in Emilia-Romagna (E-R) of Italy and the Shannon region of Ireland. In this context, technoparks established to accelerate the economic development of the development agency ERVET of Emilia-Romagna region and the development agency SD of the Shannon region have been revealed through establishment and development processes. The subject was examined by qualitative research methods using document analysis technique. The analysis yielded the following results: a)Technoparks contributed to local development through aspects such as production, employment, R\&D, innovation. b)Sectoral Innovation System and Regional Innovation System have been established by connecting technoparks via network.
\end{abstract}

Keywords: Local development, technopark model, regional innovation system, Regional Development Agency, Emilia-Romagna region, Shannon region

Paper Type: Research

\footnotetext{
${ }^{1}$ Milli Eğitim Bakanlığı (Öğretmen), fatihcelik6673@gmail.com.

Atıf için (to cite): Çelik, F. (2019) Yerel Kalkınmada Teknopark Modeli: Emilia-Romagna (İtalya) ve Shannon (İrlanda) Bölgeleri Örnekleri. Afyon Kocatepe Üniversitesi Sosyal Bilimler Dergisi, 21(4), 1112-1129.
} 


\section{Giriş}

Yerel $^{2}$ kalkınmanın sağlanması amacıyla 1930'lardan itibaren dünyanın farklı yerlerinde Bölgesel Kalkınma Ajansları (BKA'lar) kurulmaya başlanmıştır. BKA'ların ilk örneği, 1933 yılında ABD'de kurulan Tennessee Vadisi Yönetimi'dir (TVA). Avrupa'da ise, 1950'lerden itibaren İrlanda, İtalya gibi ülkelerde kurulmaya başlanmıştır. BKA'lar, yeniliklere dayalı yerel kalkınmayı sağlamak üzere teknoparklar kurmuşlar. Teknopark, bir üniversite veya araştırma kurumunun öncülüğünde üretilen bilginin ticarileştirilmesini amaçlayan bir kurumdur. BKA'ların öncülüğünde belli sektörlere yönelik teknoparklar kurularak Sektörel Yenilik Sistemi (SYS); teknoparkları bir ağ bünyesinde birleştirerek de Bölgesel Yenilik Sistemi (BYS) kurulmuştur. SYS, belli ürünleri geliştiren, üreten ve pazarlayan aktörlerden oluşan bir yapıdır. BYS ise, bilginin üretildiği, kullanıldığı, yayıldığı ve aktörlerin etkileşim içinde olduğu bir ortamdır.

Bu çalışmada, Shannon (İrlanda) ve Emilia-Romagna (İtalya) bölgelerinde uygulanan teknopark modeli incelenmiştir. Kuzey Amerika ile Avrupa arasında aktarmalı transatlantik uçuşlarının 1945 yılında Shannon üzerinden başlaması, bölge ekonomisini canlandırmıştır. Transatlantik uçuşlarının \% 85'inin yakıt ikmalinin yapıldı̆̆ı Shannon Havaalanı, dünya havayolu trafiğinde önemli bir konuma gelmiştir. 1950'lerin sonunda uzun mesafeli jet uçaklarının gelişmesiyle (post-jet dönemi) Shannon önemini kaybetmiştir. İmalat sanayi ihracatının \% 25 'inin yapıldığ Shannon, İrlanda ekonomisi için önemli bir yere sahiptir. Bu nedenle merkezi yönetim, bölgeyi yeniden canlandırmak için iki önlem almıştır. Bunlar, havaalanının altyapısının geliştirilmesi ve 1959 yılında Shannon Kalkınma Ajansı'nın (SD: Shannon Development) kurulmasıdır. SD, yerel kalkınmayı hızlandırmak için teknoparklar kurmuştur. Bunlardan ilki, 1984 yılında kurulan Ulusal Teknoloji Parki'dır (NTP). Son aşamada ise, bu teknoparkları birbirine bağlamak için Bilgi Ağı'nı (SDKN, 2001) kurmuştur.

İtalya'da merkezi yönetim, bölgelere politika geliştirme yetkisi vermiştir. Bunun üzerine Emilia-Romagna (E-R) bölgesi, bir BKA olarak 1973 yılında ERVET'i (Emilia-Romagna Valorizzazione Economica Territorio) kurmuştur. ERVET'in amac1, bölgenin küresel rekabet gücünü yenilikler temelinde artırmaktır. Bu amaçla KOBİ'lerin kümelenmesini ${ }^{3}$ sağlamak için 1970'lerden itibaren Reel Hizmet Merkezleri (RSCs: Real Service Centers) kurmuştur. RSC'leri (teknoparklar), ERVET Sistemi bünyesinde toplamıştır. 2002 yılında geliştirilen Bölgesel Yenilik Stratejisi (PRRIITT) çerçevesinde de teknopark gibi yapılar; 2007 yılında ise, bu yapıları birbirine bağlamak için İleri Teknoloji Ağı (HTN: High-tech Network) kurulmuştur. Reel Hizmet Merkezleri, bölgenin Ar-Ge ve yenilik yapma kapasitesini artırmıştır. Emilia-Romagna'ya özgü yerel kalkınma yaklaşımı, literatüre Emilian Modeli olarak geçmiştir.

Çalışmanın amacı, yerel kalkınmada bir model olarak uygulanan Teknopark Modeli’ni, Emilia-Romagna ve Shannon bölgeleri örneklerinde analiz etmektir. Dört bölümden oluşan çalışmada, ilk olarak teknopark modeli, Sektörel Yenilik Sistemi, Bölgesel Yenilik Sistemi ve Bölgesel Kalkınma Ajansları'na ilişkin kavramsal çerçeve sunulmuştur. İkinci bölümde, araştırmanın amacı, yöntemi, sınırları ve sınırlılıklar ortaya konmuştur. Üçüncü bölümde, sırasıyla Emilia-Romagna bölgesi ve kalkınma ajansı ERVET; teknoparkları (RSC'ler) bir araya getirmek suretiyle kurulan ERVET Sistemi; RSC'lerden biri olan Teknoloji Geliştirme Merkezi (ASTER) ile Bölgesel Yenilik Stratejisi ve İleri Teknoloji Ağı incelenmiştir. Son bölümde ise, öncelikle Shannon bölgesi ile Shannon Kalkınma Ajansı; daha sonra da ajansın kurduğu Ulusal Teknoloji Parkı ve Bilgi Ağı analiz edilmiştir.

\footnotetext{
${ }^{2}$ Çalışmada, yerel ve bölgesel kavramları aynı anlamda kullanılmıştır.

${ }^{3}$ Literatürde bu kavramı ilk kez kullanan M. Porter'a (1990) göre, "kümelenme, belirli bir alanda birbiriyle rekabet eden, işbirliği yapan firmaların ve bunlarla ilişkili kurumların coğrafi yoğunlaşmasıdır”. Porter (2003), ABD'nin yeniliklere dayalı küresel rekabet gücünün, kümelenme temelli Bölgesel Yenilik Sistemi’nden (BYS) kaynaklandığını tespit etmiştir.
} 


\section{Kavramsal Çerçeve}

Bu bölümde, teknopark modeli, Sektörel Yenilik Sistemi, Bölgesel Yenilik Sistemi ve Bölgesel Kalkınma Ajansları ele alınmıştır.

\subsection{Teknopark Modeli}

Teknopark, bir üniversite veya araştırma kurumunun öncülüğünde üretilen bilginin ticarileştirilmesini amaçlayan; bünyesinde Ar-Ge ve yenilik temelli firmaları barındıran bir kurumdur (Asheim ve Isaksen, 1996: 42). Bilim park1, yenilik merkezi gibi adlarla adlandırılan teknoparklarda, girişimcilere danışmanlık, risk sermayesi gibi destekler verilmektedir. Yeniliklere dayalı kalkınmaya katkıda bulunmak üzere teknopark kurulması, literatürde Teknopark Modeli olarak adlandırılmıştır (Gülbaş, 2011: 139).

Ülkelerin orta gelirden yüksek gelir düzeyine geçememesinin (Orta Gelir Tuzağı) çözüm yollarından biri, yeniliklerin geliştirilmesidir (Yalçıntaş, 2014: 87). Bu amaçla Üniversite-Sanayi İşbirliği (ÜSI) teşvik edilmektedir. Kökeni 1850'li yıllara dayanan ÜSİ, üniversitenin Ar-Ge altyapısı ve beşeri sermayesi ile sanayi sektörünün kaynaklarını (deneyim, finansman vb.) bir araya getirmek için kurulan karşılıklı etkileşim ortamıdır (Dura, 1994: 101).

Üniversite-sanayi-devlet işbirliği, Etzkowitz ve Leydesdorff'ın (1995: 15) geliştirdiği Üçlü Sarmal Modeli ile incelenmiştir. Modele göre üniversite, teknoparklarla firma kurucu; sanayi, üniversiteler için uygulamalı eğitici; devlet ise, aracı rolünü üstlenmiştir.

ÜSİ'ye ortam sağlayan kurumlardan biri, teknoparklardır. Dünyada ilk teknopark, ABD'de Stanford Üniversitesi'nde 1952 y1lında kurulan Stanford Araştırma Parkı'dır (Silikon Vadisi). Üniversitenin teşvik ettiği mezunlardan W. Hewlett ve D. Packard, 1939 yılında Palo Alto'daki bir garajda küçük bir elektronik firması (Hewlett-Packard, $\mathrm{HP}^{4}$ ) kurmuştur. Bu garaj, dünyada kümelenmenin en ünlü örneği olan Silikon Vadisi'nin kuruluş yeridir (Hospers et al., 2009: 285-286).

Silikon Vadisi, bölge ve ülke ekonomisine istihdam ve gelir bakımından önemli katkılarda bulunmuştur. Silikon Vadisi'nde, piyasa değeri 1 trilyon $\${ }^{\prime}{ }^{5}$ aşan 8 binden fazla firmada, 300 bin kişi çalışmış; ABD milli gelirinin \% 2,1'i, bulunduğu Kaliforniya eyaletinin gelirinin de \% 16's1 üretilmiştir. Bu firmalar, farklı dönemlerde Nobel bilim ödüllerinin de \% 60'ını almışlardır (Özdemir, 2014: 9-11). Silikon Vadisi'nin başarısı ile dünyada yaygınlaşan teknoparkların sayısı 4 bini aşmıştır (Yalçıntaş, 2014: 91).

Türkiye'de teknopark ${ }^{6}$ kurma çalışmaları 1980'lerde başlamıştır. İlk teknopark, Ege Üniversitesi bünyesinde 1989 yılında kurulan İzmir Teknopark'tır (Çelik, 2019a: 52). Bölgesel Kalkınma Ajansları (BKA'lar) da teknoparkların kurulmasına öncülük etmiştir. Bu kapsamda BKA'lar, Karaman İş Geliştirme Merkezi (2011), Konya Bölgesel İnovasyon Merkezi (2011), Çorum Teknoloji Geliştirme Bölgesi (2012), İzmir İnovasyon Merkezi (2012) gibi yapıların kurulmasını desteklemiştir (KB, 2012: 78-80; KB, 2013: 86-87). Günümüzde 84 tane teknopark olup; 23 tanesi geliştirme aşamasındadır. Teknoparklarda Ar-Ge faaliyeti yapan firma sayısı 5.219 olup; bunların \% 37'si yazılım sektöründedir. 2018 yılı itibariyle yaklaşık 50 bin personelin istihdam edildiği teknoparklarda, 30 bin Ar-Ge projesi tamamlanmış, 1.053 tane patent tescil ettirilmiş ve 3,6 milyar \$ tutarında teknolojik ürün ihracatı yapılmışıır?

Emilia-Romagna bölgesindeki teknoparklar (RSC'ler), kimi yazarlarca analiz edilmiştir. Bunlardan Pietrobelli ve Rabelloti (2002), literatürde Bölgesel Yenilik Sistemi'nin (BYS) önemli bir unsuru olan ve İtalya'da Reel Hizmet Merkezi (RSC'ler) olarak adlandırılan İş Geliştirme

\footnotetext{
${ }^{4}$ HP, bir spin-off olarak kurulmuştur (Hospers et al., 2009: 285). Spin-off, teknoloji yoğun firmalarda veya üniversitelerde Ar-Ge faaliyetleri ile geliştirilen ürünler/sistemler için alınan lisansı/patenti ticarileştirmek üzere kurulan bir firmadır.

${ }^{5} \mathrm{Bu}$ tutar, çok sayıda ülkenin milli gelirinden daha büyüktür.

${ }^{6}$ Türkiye'de, 4691 sayılı yasada teknopark kavramı yerine Teknoloji Geliştirme Bölgeleri kavramı kullanılmıstır.

${ }^{7}$ https://teknopark.sanayi.gov.tr/Agtm/AnnouncementDetail?YVfJmcnnrXMtnNIpQ6gdaR8vdUPzmO6kRJLf8F4Jdmg\%253d=I5Q OyVUMgy7XvbLWKeGgBA\%253d\%253d (Erişim tarihi: 07.09.2019).
} 
Merkezi'ni (BDS), Emilia-Romagna, Lombardia ve Veneto bölgeleri örneğinde incelemişlerdir. Reel Hizmet Merkezleri'nin aktörler arasında ağ (aracılık) rolünü üstlendiğini ve KOBİ’lerin rekabet gücünü artırdığını belirlemişlerdir.

Bardi ve Bertini (2004), Emilia-Romagna'da ÜSİ'nin yerel kalkınmaya etkisini analiz etmişler. RSC'lere duyulan ihtiyaç üzerine kurulan CITER'in ${ }^{8}$, KOBİ'lerin yeniliklere dayalı küresel rekabet gücüne katkısını ele almışlar. Analizle Emilia-Romagna'nın küresel piyasalara katılmasıyla KOBİ'lerin mikro düzeyden meso (bölge) düzeye dönüştüğünü tespit etmişlerdir.

Marzocchi (2009), Emilia-Romagna'nın Bölgesel Yenilik Stratejisi'ni (PRRIITT) inceleyerek, kurumsallaşma bakımından üç tane gelişme tespit etmiştir. İlki, bölgede bir BKA olarak ERVET kurulmuştur. İkincisi, informal üretici ağları sistemini formal hale getirmek için RSC'ler açılmıştır. Üçüncüsü ise, yeni bir yerel kalkınma stratejisi (PRRIITT) geliştirilmiştir.

López-Estornell (2011), Emilia-Romagna ve Valencia'daki yenilik politikalarını ele almıştır. Bu bölgelerde yenilik politikalarının, RSC'lere ve Ar-Ge kurumlarına yoğunlaştığını ve KOBİ'lerin ileri teknoloji hizmetlerine erişimini sağladığını belirlemiştir.

Kimi yazarlar da Shannon bölgesindeki teknoparkları incelemişlerdir. Bunlardan Çelik (2015 ve 2018), Shannon Kalkınma Ajansı'nın (SD) yenilikçilik faaliyetleri ile kurulan teknoparkları ele almıştır. Çelik ve Yıldız (2015) ise, SD ile Limerick Üniversitesi'nin (UL, 1972) bölgesel kalkınmaya yönelik işbirliği faaliyetlerini analiz etmişler. Literatüre SD-UL Modeli olarak geçen bu işbirliğinin ilk somut örneği, Ulusal Teknoloji Parkı'nın (NTP, 1984) kurulmasıdır. Analizlerinde, Shannon Kalkınma Ajansı'nın ve Limerick Üniversitesi'nin yerel kalkınmada yenilikçiliğin belirleyicileri olduklarına kanaat getirmişlerdir.

\subsection{Sektörel Yenilik Sistemi ve Bölgesel Yenilik Sistemi}

Yenilik, Oslo Klavuzu'na göre süreç olarak "bir fikri pazarlanabilir bir ürün ya da hizmete, yeni ya da geliştirilmiş bir imalat ya da dağıtım yöntemine ya da yeni bir toplumsal hizmet yöntemine dönüş̧ürme" faaliyetidir (Oğuztürk, 2003: 254-255). Yenilik konusunda 1980'lerde öncülüğünü C. Freeman ve B-A Lundvall'ın yaptığı sistem yaklaşımı geliştirilmiştir. $\mathrm{Bu}$ yaklaşıma göre teknolojik değişim ve yenilik, çok sayıda aktörün işbirliği ile ortaya çıkan evrimsel bir süreçtir (Oğuztürk, 2006: 124-125).

Sistem yaklaşımına dayalı olarak 1980'lerde Ulusal Yenilik Sistemi (UYS); 1990'larda Bölgesel Yenilik Sistemi (BYS); 2000'lerde ise, Sektörel Yenilik Sistemi (SYS) geliştirilmiştir (Kiper, 2013: 8). Öncülüğünü Freeman (1987) ve Lundvall'ın (1992) yaptığı Ulusal Yenilik Sistemi, bir ülkede yenilik faaliyetlerini yürüten aktörlerden oluşmaktadır.

Sektörel Yenilik Sistemi, belli ürünleri geliştiren, üreten ve pazarlayan aktörlerden oluşan bir yapıdır. Bir sektördeki aktörlerin etkileşimi, formal ya da informal nitelikte olabilir. İşletmeler, Ar-Ge gibi alanlarda işbirliği (formal); fuar gibi ortamlarda (informal) etkileşim içinde olabilirler. $\mathrm{Bu}$ sistemde yenilikler, firmaların formal ve informal etkileşimi ile gerçekleşir (Oğuztürk, 2006: 128). Sektörel Yenilik Sistemi'nin gelişmesinde K. Pavitt'in (1984) önemli katkısı olmuştur (Kiper, 2013: 10).

Bölgesel Yenilik Sistemi ise, Ulusal Yenilik Sistemi’nin bölgeye uyarlanmasıdır. Yenilik temelli bölgesel politika anlayışı ile geliştirilmiştir. Bilginin üretildiği, kullanıldığı, yayıldığı ve aktörlerin etkileşim içinde olduğu bir ortamdır (Oğuztürk, 2003: 268). Emilia-Romagna, BadenWürttemberg gibi bölgelerin kalkınmasını açılamak üzere P. Cooke (1998) tarafından 1990'larda geliştirilmiştir. Cooke, Roper ve Wylie'ye (2001) göre, başarılı bir Bölgesel Yenilik Sistemi'nin başlıca ortak özellikleri şunlardır: İşletmeler arası işbirliği, nitelikli işgücü, destekleyici kurumsal altyapı, yenilikçi kültür, aktif bölge yönetimi ve yeniliklere yönelik yerel

\footnotetext{
${ }^{8}$ CITER (Tekstil Bilgi Merkezi), E-R'nin Carpi kentinde tekstil firmalarının yeni teknolojilere uyum sağlaması için 1980'de kurulmuştur. Yenilikler ve bilgi transferi yapılmasi; Ar-Ge kurumları, üniversiteler ve firmalar arasında ağlar kurulması; küresel piyasalara ilişkin bilgi verilmesi gibi alanlara yoğunlaşmıştır (Clara, 1999: 1;Cooke, 1996: 54-55).
} 
yönetişimdir (Sungur ve Keskin, 2009: 117). Teknoparklar, Bölgesel Yenilik Sistemi için gerekli olan işbirliği, işgücü, altyapı gibi unsurları bir araya getiren kurumlardan biridir.

Bölgesel Yenilik Sistemi'ne yönelik politikalar ve araçlar, bölgeye özgü olarak değişmektedir. Park (2001), bu konuda beş tane öneri sunmuştur. Bunlar, kümelenmenin desteklenmesi, yenilik ve girişimcilik için kolaylaştırıcı ortam sağlanması, sosyal sermaye stokunun oluşturulması, öğrenme ve yenilik ağları ile yerel ve küresel ağların kurulmasıdır (Sungur ve Keskin, 2011: 166).

Bölgesel Kalkınma Ajansları (BKA'lar), yenilikçi ağları içeren Bölgesel Yenilik Sistemi (BYS) kurmuşlar. Yenilikler, çok düzeyli işbirliğini gerektirmiştir (Cooke, 2004: 513; Uyarra ve Haarich, 2002: 2). Bu bakımdan Bölgesel Yenilik Sistemi, iki alt sistemden oluşmuştur. Bunlar, bilgi üretme ve yayma alt sistemi (bilginin üretilmesi ve yaygınlaştırılması ile uğraşan kurumlar) ile bilgiyi uygulama ve kullanma alt sistemidir (firmalar, müşteriler, tedarikçiler, rakipler, ortaklar) (Tödtling ve Trippl, 2005: 1205; Camagni ve Capello, 2012: 8). Cooke'a (2001) göre, bu iki alt sistemin etkileşimi ile Bölgesel Yenilik Sistemi ortaya çıkar (Uyarra, 2008: 12).

$\mathrm{AB}$, yenilik sürecinde arz ve talep tarafının (iki alt sistemin) etkileşimini sağlamıştır (Landabaso ve Reid, 1999: 18). Kimi aktörlere de bu konuda aracılık rolünü vermiştir. Buna göre Bölgesel Yenilik Sistemi, Şema 1'de sunulduğu gibi başlıca üç aktörden oluşmuştur (Cooke ve Memedoviç, 2003: 10).

Şema 1. Bölgesel Yenilik Sistemi’nin tarafları

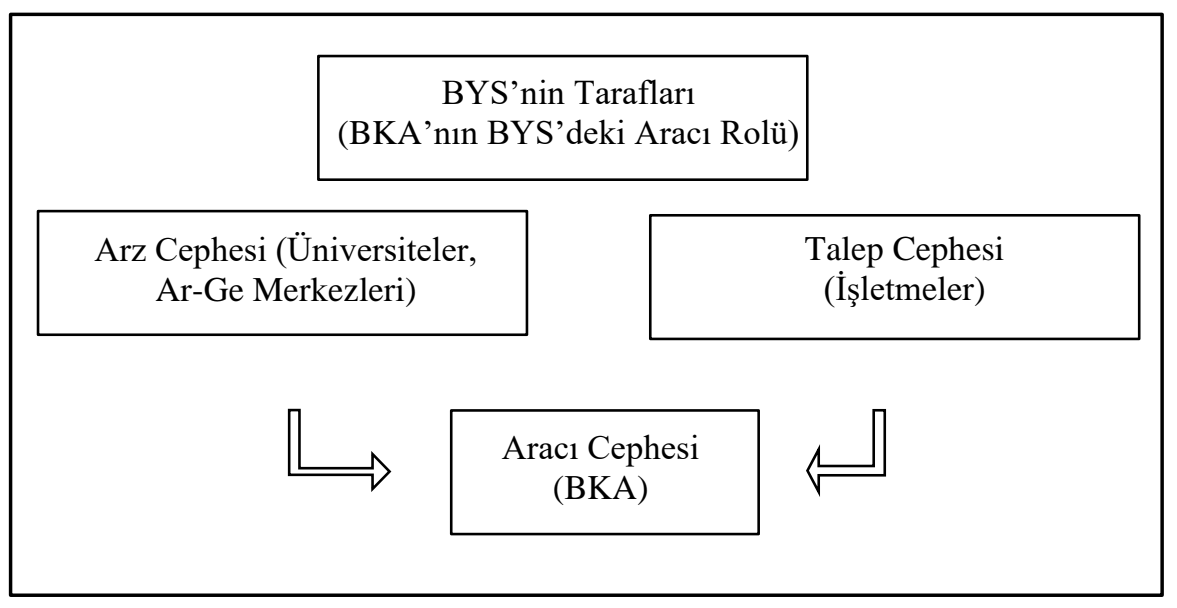

Kaynak: Çelik, 2015: 193.

Şema 1'e göre Bölgesel Yenilik Sistemi'nin arz tarafinda, bilgi üreten üniversiteler ve Ar-Ge merkezleri; talep tarafında, bilgiyi kullanan firmalar; aracı tarafında ise, bunları bir araya getiren kurumlar yer almıştır (Sungur ve Keskin, 2011: 163). Bölgesel Kalkınma Ajansları, Bölgesel Yenilik Sistemi'nin arz ve talep cephesini bir araya getiren aracı taraf rolünü üstlenmiş; bu iki tarafın yeniliklere yönelik işbirliği yapmasını sağlamıştır.

\subsection{Bölgesel Kalkınma Ajansı}

Büyük Bunalım'dan (1929) sonra yerel aktörler arasında işbirliğini sağlamak, içsel ve dışsal kaynaklara dayalı bölgesel kalkınmayı hızlandırmak için Bölgesel Kalkınma Ajansları (BKA'lar) kurulmuştur. BKA'ların amacı, bölgesel kalkınmayı sağlamak ve bölgeler arası eşitsizlikleri azaltmaktır. Merkezi ve/veya yerel aktörler tarafindan finanse edilirler ve yönetilirler; yerel kalkınma stratejileri hazırlamak, aktörler arasında işbirliğini sağlamak, bölgenin Ar-Ge ve yenilik yapma kapasitesini geliştirmek için teknopark vb. yapılar kurmak gibi faaliyetlerde bulunurlar (EURADA, 1999: 34-35, 65; Çelik, 2015: 39-40).

BKA'lar, verdikleri hizmetler bakımından geleneksel ve yenilikçi BKA'lar şeklinde iki gruba ayrılır. Geleneksel BKA'lar, bölgeye yabancı yatırım çekmek için danışmanlık hizmeti 
verirler. Yenilikçi BKA'lar ise, yönetim, piyasa ve üretim gibi alanlarda danışmanlık hizmeti sunarlar. Finansal olarak işletmelere, özsermaye ve kredi desteği sağlarlar. Bölgenin yenilik yapma kapasitesini artırmak için de teknoparkların kurulmasını desteklemiş ve eğitim hizmetleri verirler (EURADA, 1999: 18-19; Çelik, 2018: 15; Çelik, 2019b: 876).

BKA'lar, yenilikçilik faaliyetleri ${ }^{9}$ ile Bölgesel Yenilik Sistemi kurmuştur. Bu amaçla teknoparklar gibi yapılar kurarak, firmalara yenilik desteği, teknoloji transferi gibi "rekabet öncesi” hizmetler ("reel hizmet”ler) vermiştir (Pietrobelli ve Rabelloti, 2002: 9). Reel hizmetler şunlardır (EURADA, 1999: 110, 149): Pazarlar, ürünler, rekabet ve teknolojik gelişmeler hakkında bilgi vermek; mesleki eğitim; teknolojik yayılma; küresel işbirliğinin geliştirilmesi. Bölgesel Yenilik Sistemi'nin temel bir unsuru olarak kabul edilen Reel Hizmet Merkezleri (RSCs), teknopark, yenilik merkezi gibi isimlerle adlandırılmıştır (Bellini, 2000: 711-712; Clara, 2000: 4).

\section{Araştırmanın Amacı, Yöntemi, Sınırları ve Sınırlılığı}

İrlanda'da Shannon Havaalanı'nın önemini kaybetmesi üzerine 1959 yılında Shannon Kalkınma Ajansı (SD) kurulmuştur. SD'nin temel amacı, havaalanının yeniden eski cazibesine kavuşmasıdır. Bu amaçla havaalanının yakınında kurulan ve dünyanın ilk Serbest Bölgesi olan Shannon Serbest Bölgesi'ni (SFZ) yönetmiştir. SFZ, çeşitli sektörlerden yerli ve yabancı firmaların kümelenmesini sağlamıştır. SD yerel kalkınmayı hızlandırmak için ayrıca teknoparklar kurmuştur. Bunlardan ilki, 1984 yılında kurulan Ulusal Teknoloji Parkı'dır (NTP). Son aşamada ise, bu teknoparkları birbirine bağlamak için Bilgi Ağı'nı (SDKN) kurmuştur.

İtalya'nın Emilia-Romagna bölgesinde 1973 yılında bir BKA olarak kurulan ERVET, bölgenin küresel rekabet gücünü yenilikler temelinde artırmak için KOBİ'lerin kümelenmesini sağlamak üzere 1970'lerden itibaren Reel Hizmet Merkezleri (RSCs) kurmuştur. RSC'leri, ERVET Sistemi bünyesinde toplamıştır. 2002 yılında geliştirilen Bölgesel Yenilik Stratejisi (PRRIITT) çerçevesinde de teknopark gibi yapılar; 2007 y1lında ise, bu yapıları birbirine bağlamak için İleri Teknoloji Ağı (HTN) kurulmuştur. Emilia-Romagna’ya özgü yerel kalkınma yaklaşımı, literatüre Emilian Modeli olarak geçmiştir.

Araştırmanın amacı,1950’lerden itibaren yerel kalkınmada bir "model” olarak uygulanan Teknopark Modeli'ni, Emilia-Romagna ve Shannon bölgeleri örneklerinde analiz etmektir. Konu, nitel araştırma yöntemlerinden doküman analizi tekniği ile ele alınmıştır. Doküman analizi, konuya ilişkin yazılı materyallerin incelenmesidir. Bu analiz, beş aşamada yapılabilir. Bunlar, dokümanlara ulaşma, orijinalliğini kontrol etme, dokümanları anlama, verileri analiz etme ve kullanma (Yıldırım ve Şimşek, 2013: 217-218, 223). Bu doğrultuda çalışma, doküman analizi çerçevesinde beş aşamada hazırlanmıştır.

Çalışma, Emilia-Romagna ve Shannon bölgelerindeki teknopark modelinin kuruluş ve gelişme süreçlerinin analizi ile sınırlandırılmıştır. Araştırmanın sınırlılığı ise, teknoparkların yerel kalkınmaya üretim, yatırım, istihdam, yenilik gibi katkılarına dair istatistik verinin kısıtlı olmasıdır. Bu sınırlılık, araştırmalardan ve kurumların dokümanlarından derlenen verilerle aşılmaya çalışılmıştır.

\section{Emilia-Romagna Bölgesi (İtalya)}

Emilia-Romagna, İtalya'daki yirmi bölgeden biridir. Yaklaşı 4,5 milyon (İtalya'nın \% 7'si) nüfusa sahiptir. Ekonomik kalkınmada, ülkenin Üçüncü İtalya kesimindeki en başarılı bölgedir (Humphrey ve Schmitz, 1995: 2). Bölgesel kalkınmada en çok analiz edilen yerlerden biridir. Yerel kalkınma yaklaşımı, literatürde "esnek uzmanlaşmaya dayalı kalkınma modeli" olarak kabul edilir (Capecchi, 1992; Bianchi ve Labory, 2011: 439).

\footnotetext{
${ }^{9}$ Yenilikçilik faaliyetleri, bölgenin yenilik yapma kapasitesini geliştirmeye yönelik kümelenme, yenilik ve ağ faaliyetleri şeklinde tanımlanabilir. Bölgenin yenilik yapma kapasitesi, yerel aktörlerin işbirliği yapma yeteneği, yenilikçi girişimcilerin desteklenmesi, Ar-Ge altyapısı gibi unsurlarla ilişkilidir (Çelik, 2015: 4).
} 
Brusco (1982), Emilia-Romagna bölgesine özgü kalkınma yaklaşımını Emilian Modeli ${ }^{10}$ olarak adlandırmıştır. Modelin başlıca özelliklerinden biri, bölge ekonomisinin KOBİ'lere ve zanaatkarlara dayanmasıdır. İkincisi ise, bölgede verilen eğitim ile firmalarda mesleki tecrübeyle kazanılan eğitimdir (Manuelli, 2002: 7).

Emilian Modeli, Üçüncü İtalya'nın kalkınmasını açıklamak için literatürde en çok atıf yapılan örnek olmuştur. Bu ilginin nedenlerinden biri, bölgedeki KOBİ'lerin işbirliği yeteneği, üretim yapısı ve küresel rekabet gücüdür. Diğeri ise, bölge yönetiminin, iş dünyası ile merkezi yönetim arasındaki aracılık rolüdür (Cocchi, 2011: 17).

Bölge, gelişmiş bir Ar-Ge altyapısına sahiptir. 2012 yılında Ar-Ge'ye tahsis edilen ulusal kaynakların \% 5,9'unu kullanırken; Ar-Ge çıktısının \% 15'ini sağlamıştır (ASTER, 2012: 4). Bu durum bölgenin Ar-Ge alanındaki etkinliğini göstermiştir. Bölgede, 6 üniversite ve Ar-Ge kurumları (9 bin) ile firmalar (14 bin) dahil toplam 23 bin araştırmacı çalışmıştır (ASTER: 4; EC, 2013: 4-5).

1970'lerde ülkenin yoksul bölgelerinden biri olan Emilia-Romagna, 2000'li y1llarda Avrupa'nın en gelişmiş ve en yenilikçi bölgelerinden biri olmuştur. Kişi başına milli geliri (31.900 €), ulusal ortalamadan \% 27 daha fazladır. GSYİH'sı son 10 yılda istikrarlı bir şekilde artan bölge, Avrupa'nın orta-ileri yenilik bölgesi grubunda yer almıştır (Ederer et al., 2011: 22, 24).

İtalya'da 1970'lerde bölgelere "kalkınma ve gelişme kurulları" (ajans) kurma yetkisi verilmiştir (Marzocchi, 2009: 45). Bunun üzerine Emilia-Romagna yönetimi, bir BKA olarak ERVET'i kurmuştur. ERVET, bölgenin küresel rekabet gücünü yeniliklerle artırmak üzere Reel Hizmet Merkezleri'nin (RSC'ler) kurulmasına öncülük etmiştir. RSC'lerin de katkısıyla bölge, Brusco'nun analizinden "20 yıl sonra" Avrupa'nın en zengin bölgelerinden biri olmuştur (Mosconi ve Mantovi, 2010: 11).

$\mathrm{Bu}$ bölümde öncelikle Emilia-Romagna'daki teknoparkların kurucu aktörlerinden ERVET ile Reel Hizmet Merkezleri'nin bir araya getirilmesiyle oluşturulan ERVET Sistemi incelenmiştir. Daha sonra Reel Hizmet Merkezleri'nden Teknoloji Geliştirme Merkezi (ASTER), Bölgesel Yenilik Stratejisi (PRRIITT) ve İleri Teknoloji Ağı (HTN) ele alınmıştır.

\subsection{ERVET: Emilia-Romagna Kalkınma Ajansı}

ERVET, Ulusal Esnaf Federasyonu'nun (CNA) yenilik merkezleri sistemi oluşturulması için bölge yönetimine baskı yapması üzerine 1973 yılında kurulmuştur. ERVET'in amac1, KOBI'leri geliştirerek yerel kalkınmayı hızlandırmaktır (E-R, 2005: 35). Bölge yönetiminin, bankaların ve meslek odalarının ortak olduğu bir holdingtir (Marzocchi, 2009: 45). Yönetim kurulu, denetçiler kurulu ve bölüm şefleri şeklinde örgütlenmiştir (Maccani, 2007: 9, 23). RSC'ler dahil yaklaşı 180 kişi istihdam edilmiştir (ERVET: 3 ). Finansmanı, bölge yönetimi (\% 58), AB fonları (\% 19) ve meslek odaları (\% 23) tarafından karşılanmıştır.

ERVET, bölge yönetiminin, geri kalmış yerlerin sanayileşmesini hedeflemesi ile başlangıçta zanaat üretim süreçlerini geliştirmeye yoğunlaşmıştır. Bölgede sanayileşmenin dengesiz dağılımını gidermek üzere bu politikanın 1980'lerde değiştirilmesiyle KOBİlerin kümelenmesi için Reel Hizmet Merkezleri; bunları birleştirerek de bir ağ (ERVET Sistemi) kurmuştur (López-Estornell et al., 2012: 10).

\subsection{ERVET Sistemi: Reel Hizmet Merkezleri}

Literatürde İş Geliştirme Hizmeti olarak da adlandırılan Reel Hizmet Merkezleri (RSC'ler), Avrupa'da ve Amerika'da bilim park1, teknopark, yenilik merkezi gibi isimlerle kurulmuştur (Bellini, 2000: 711-712; Clara, 2000: 4). RSC'ler, firmalara yenilik desteği, teknoloji transferi gibi hizmetler vermiştir.

\footnotetext{
${ }^{10}$ Emilian Modeli hakkında ayrıntılı bilgi için bakınız: Çelik (2019c).
} 
Emilia-Romagna'nın Avrupa'nın en zengin bölgelerden biri olması, kümelenme politikası ile açıklanmıştır. Bölgede endüstriyel alanlar olgusu temelinde 1970’lerde uygulanmaya başlanan kümelenme politikası ile Reel Hizmet Merkezleri kurulmuştur (Bardi ve Bertini, 2004: 10-11). Bu politikanın en somut örneği, ERVET Sistemi’dir.

Emilia-Romagna'da KOBİ'lerde yenilikleri ve rekabet gücünü geliştirmek için 1980'lerden beri kullanılan başlıca politika aracı, Yenilik Merkezleri'dir (RSC'ler) (Pietrobelli ve Rabelloti, 2002: 13; Bianchi ve Labory, 2011: 440). RSC'ler, düşük eğitimli ve teknik yardıma ihtiyaç duyan ilk jenerasyon girişimcilere piyasada sunulmayan hizmetleri vermek üzere kurulmuştur. ERVET, RSC'ler aracılığıyla bölgede Ar-Ge ve yenilik faaliyetlerini desteklemiştir (Pfleger, 2004: 2). Yerel ekonomilerin sektörel uzmanlaşmasına göre bölgenin farklı yerlerinde kurulan RSC'ler (Marzocchi, 2009: 48-49), Tablo 1'de sunulmuştur.

Tablo 1. ERVET Sistemi: Reel Hizmet Merkezleri (RSC'ler)

\begin{tabular}{llll}
\hline Y11 & Kent & RSC'nin Ad1 & \multicolumn{2}{c}{ RSC'nin Faaliyet Alanı } \\
\hline & & & Sektörel Merkezler \\
\hline 1976 & Bologna & Ceramic & Seramik \\
1980 & Modena & Citer & Giyim \\
1982 & Ferrara & Cemoter & Erozyon için makineleşme \\
1983 & Emilia & Cesma & Tarım makineleri \\
1983 & Forli & Cercal & Ayakkab1 \\
1985 & Bologna & Quasco & İşaat \\
1993 & & Democenter & Makine \\
1994 & & Del suelo a la mesa & Tarım-Gıda \\
& Parma & Fit & Teknolojik yenilik \\
& & Earth & Tarım-Gıda \\
& Bologna & Cetas & Tarım uzmanlarının eğitimi \\
& Modena & Spot & Metal ve mekanik sektörleri \\
1984 & Faenza & Agenzia Polo Ceramico & Seramik \\
1985 & Bologna & Aster & Bütün sektörler (teknoloji-yenilik) \\
1985 & Bologna & Cermet & Metal (teknolojik danışmanlık) \\
1986 & Ravena & Ase & Bütün sektörler \\
1986 & Parma & Resfor & Mekanik (ağ hizmeti) \\
1989 & & Svex & İhracatı geliştirme \\
\hline
\end{tabular}

Kaynak: Marzocchi, 2009: 50; López-Estornell, 2011: 10; López-Estornell et al., 2012: 30.

Tablo 1'e göre Reel Hizmet Merkezleri, sektörel ve fonksiyonel olmak üzere iki gruba ayrılmıştır. Sektörel merkezler, firmalarda üretim sürecinin ve teknolojik kapasitenin geliştirilmesinden sorumlu olmuştur. Fonksiyonel merkezler ise, üretim ağları, ihracat ve teknolojik gelişme gibi alanlara yoğunlaşmıştır. Bunlardan Aster ve Svex, tüm sektörlere hizmet vermiştir (Marzocchi, 2009: 49).

RSC'ler, yerel aktörlerin işbirliğine güzel bir örnektir. Yaklaşık 1.000 firmayı içermiştir. Amacı, firmaların Ar-Ge faaliyetlerini desteklemektir. Yönetimi, ağırlıkı olarak girişimciler ile meslek odalarının temsilcilerinden oluşmuştur (ERVET: 2). İşletmelere teknoloji transferi, ArGe, finansman gibi alanlarda danışmanlık yapmıştır (Pfleger, 2004: 3). Bölge yönetiminin ve ERVET'in finanse ettiği RSC'ler, sundukları hizmetlerden de gelir sağlamıştır.

Küresel rekabet sonucu bazı firmaların yenilik desteği için üniversitelere başvurması üzerine RSC'ler yeniden yapılandırılmıştır (Bardi, 2007: 170). En etkin olanları (Aster, Citer ve Democenter gibi) geliştirilirken; bazıları da kapatılmış veya birleştirilmiştir (Rinaldi, 2002: 19; Marzocchi, 2009: 55). RSC'ler birleştirilerek ERVET Sistemi (ăg) kurulmuştur. Bir tür Bölgesel 
Yenilik Sistemi olarak kabul edilen ERVET Sistemi, bölge yönetimi (\% 42), özel sektör (\% 38), $\mathrm{AB}(\%$ 14) ve kamu kurumları (\% 6) tarafindan finanse edilmiştir (Maccani, 2007: 16).

ERVET Sistemi, RSC'ler aracılığıyla AB'nin Ar-Ge ve eğitim programlarına katılmıştır. Bazı RSC’ler (Aster, Citer, Democenter), küresel düzeyde projeler uygulamıştır. ERVET de KOBİ'lerin desteklenmesine yönelik deneyimlerini paylaşmış; G. Amerika, K. Afrika gibi ülkelerde RSC benzeri yapılar kurmuştur (ERVET: 3,5 ).

Kısaca, Emilia-Romagna'nın yerel kalkınma yaklaşımları ve araçları, üç aşamada incelenir. Bunlar, teknoparkların ve RSC'lerin kurulması ile yeniliklerden ASTER'in sorumlu olmasıdır (Gagliardi et al., 2007: 10-11). Bu kesimde ASTER ile onun öncülüğünde geliştirilen Bölgesel Yenilik Stratejisi (PRRIITT) ve İleri Teknoloji Ağı (HTN) incelenmiştir.

\subsubsection{Teknoloji Geliştirme Merkezi}

Teknoloji Geliştirme Merkezi (ASTER), yeniliklerden sorumlu bir Reel Hizmet Merkezi olarak 1985 yılında kurulmuştur. Amac1, teknoloji transferinin, yeniliklerin ve üretim sisteminin geliştirilmesidir (Bianchi ve Labory, 2011: 440). Bölgenin bilgi ekonomisine dönüşmesine katkıda bulunmak üzere 2001 yılında yeniden yapılandırılmıştır (Bologni, 2013: 7). Yenilik politikasının (PRRIITT, 2002) sorumluluğunu üstlenmiştir.

ASTER, bölge yönetiminin, üniversitelerin ve Ar-Ge merkezlerinin işbirliğinde yönetilmiştir (E-R, 2005: 35-38). 45-50 arasında personel istihdam edilmiştir. Finansmanını ERVET (\% 25), AB (\% 50) ve KOBİ'ler (\% 25) sağlamıştır. Gelir sağlamak için Birleşmiş Milletler ve Dünya Bankası ile Brezilya, Doğu Avrupa ve G. Afrika'da danışmanlık yapmıştır (Bandini, 2008: 5, 7).

ASTER, Ar-Ge, teknoloji transferi, işgücünün eğitimi gibi projeleri koordine etmiştir. Bölge için stratejik öneme sahip tematik alanlarda faaliyet göstermiştir. Araştırmacıları ve girişimcileri, finansman, teknoloji arz ve talebi, Ar-Ge kurumları ile işbirliği gibi konularda desteklemiştir (Bonaretti: 13).

ASTER'in öncülüğünde 2000'li yıllarda yenilikçi faaliyetler yürütülmüştür. Mesela Bölgesel Yenilik Stratejisi (PRRIITT) uygulanmış; bölgenin Ar-Ge altyapısını birbirine bağlamak için İleri Teknoloji Ağı kurulmuştur (Maccani, 2007: 10-13; Cocchi, 2011: 18).

\subsubsection{Bölgesel Yenilik Politikası}

Emilia-Romagna'da kalkınma politikası, 1980'ler ve 1990'lardaki sanayi politikasından (sanayi toplumu) 2000'lerde yenilik politikasına (bilgi toplumu) doğru gelişmiştir (Bandini, 2008: 6). Bölge yönetimi, 2002 yılında yenilik politikasını (PRRIITT ${ }^{11}$ ) geliştirmiş ve sorumluluğunu ASTER'e vermiştir. PRRIITT'in amac1, KOBİ'lerde Ar-Ge ve teknoloji transferi faaliyetlerini desteklemektir. Yenilikler özellikle de ürün ve süreç yeniliklerinin yapılması ile firmalar ve ArGe kurumları arasında işbirliğini geliştirmeyi amaçlamıştır (Marzocchi, 2009: 62).

PRRIITT kapsamında 2003-2011 yılları arasında laboratuvar, yenilik park1 gibi Ar-Ge merkezleri kurulmuş; bu kurumlarda araştırmacılar istihdam edilmiş, üniversite-firma işbirliği ile yenilikler yapılmış ve patentler alınmıştır. Mesela 2003-2005 döneminde Ar-Ge altyapısına, yararlanıcıların eş-finansmanı dahil 367,5 milyon $€$ yatırım yapılmıştır. İlk (2005) sonuçlara göre, 12 endüstriyel laboratuvar, 27 teknoloji transferi laboratuvarı, 24 yenilik merkezi ve 6 yenilik park1 kurulmuştur (Bandini, 2006: 17; EC, 2011: 49). Daha sonra 2008 y1lında 14 laboratuvar ve 8 merkez; 2011 yılında da 37 laboratuvar ve 11 yenilik merkezi açılmıştır (Serafini, 2011: 3). Bu kurumlarda yaklaşık 1.300 firma ve 1.500 araştırmacı yer almıştır. 2006 yılında maliyeti yaklaşık 236 milyon $€$ olan 529 tane projenin \% 92'si, Ar-Ge personeli istihdamına; \% 93'ü, üniversiteAr-Ge merkezi işbirliğine; \% 68'i de patent tesciline yöneliktir (Vecchio, 2008: 16-17, 23).

\footnotetext{
${ }^{11}$ PRRIITT hakkında ayrıntılı bilgi için bakınız: Çelik (2019d).
} 


\subsubsection{Illeri Teknoloji Ă̆}

Emilia-Romagna'da yeniliklere yönelik özel teşviklerden biri PRRIITT, diğeri ise İleri Teknoloji Ağı'dır (HTN) (ERVET, 2008: 7). HTN, PRRIITT çerçevesinde araştırma, yenilik ve teknoloji transferi faaliyetlerini geliştirmek için üniversiteler, RSC'ler ve yenilik merkezlerinin ağ1 olarak 2007 yılında kurulmuştur (CUP, 2010: 25). 88 tane Ar-Ge kurumunu barındırmıştır. Yaklaşık 2.600 araştırmacının çalıştığı bu kurumların misyonu, üniversitelerin Ar-Ge faaliyetlerini, firmaların ihtiyaçlarına göre düzenlemektir (Cocchi, 2011: 18; EC, 2013: 16).

HTN'nin amacı, Ar-Ge kurumları arasında işbirliğini sağlamaktır. ASTER'in yönettiği HTN, bölge yönetimi ve AB tarafından finanse edilmiştir (ERVET, 2008: 7-8). Faaliyetleri, tematik platformlar ve teknokutuplar aracılığıyla yürütülmüştür. HTN, şu 6 tematik platforma göre organize edilmiştir: Tarım-gıda, inşaat, enerji ve çevre, bilişim teknolojileri ve tasarım, mekanik ve materyaller, yaşam bilimi (Bonaretti: 6 ).

AB'nin de desteğiyle bölgede 2010 yllında 10 tane teknokutup kurulmuştur. Teknoparkların amacı, araştırma arz ve talebi arasında işbirliğini sağlamaktır. Araştırma kurumlarına ve firmalara, Ar-Ge ve teknoloji transferi hizmeti vermişler. HTN'nin merkezi, Bologna Teknokutubu tarafından yönetilmiştir (CUP, 2010: 16-17).

Toparlayacak olursak; Emilia-Romagna'nın kalkınmasına yönelik geliştirilen politikalar, Reel Hizmet Merkezleri'nden Bölgesel Yenilik Stratejisi'ne, buradan da İleri Teknoloji Ağı'na doğru değişmiştir. Bu bakımdan Emilia-Romagna, bir bölgenin yenilik sistemine dönüşmesi için geliştirilen politikalara örnek olmuştur. Cooke (2001), Emilia-Romagna'da yenilik sistemine dönüşümü vurgulamıştır (Bianchi ve Labory, 2011: 439, 443).

Emilia-Romagna'nın yerel kalkınmadaki "başarı hikayesi", güçlü bir yönetişim ${ }^{12}$ sisteminin ürünüdür (E-R, 2007: 7). Bu konuda Brusco (1990, 1992), Best (1990), Murray (1991), Pyke (1992) ve Garmise (1994), kurumsallaşma, işbirliği ve Reel Hizmet Merkezleri'nin (RSC'ler) kurulmasında Emilia-Romagna bölge yönetiminin önemini (Humphrey ve Schmitz, 1995: 4); Pyke (1994) ise, "firmalar arası işbirliği”ni ve bölgesel düzeyde "kurumsal altyapı desteği”ni (RSC'ler) vurgulamışlardır (Asheim, 1995: 9).

\section{Shannon Bölgesi (İrlanda)}

İrlanda'nın Shannon bölgesi, yaklaşı 455 bin nüfusa sahiptir. Clare, Limerick, Kuzey Tipperary, Güney Offaly ve Kuzey Kerry kentlerinden oluşmuştur. Yaklaşı 185 bin nüfusu ile bölgenin en büyük kenti olan Limerick, ülkede Dublin ve Cork'tan sonra başlıca ekonomik bölgedir (OECD: 2). Bölgenin kalkınması, Shannon Havaalanı, Shannon Kalkınma Ajansı (SD), Limerick Üniversitesi (UL) ve Limerick Teknoloji Enstitüsü tarafından yönlendirilmiştir.

Shannon Kalkınma Ajansı'nın öncülügündeki ekonomik kalkınma ile istihdamın sektörel dağılımı 1971-1997 yılları arasında şöyle değişmiştir: Tarım \% 32,3 - \% 11,9, sanayi \% 25,7- \% 29,1 ve hizmetler \% 35,6 - \% 47 (Boucher, 2000: 10). Bölge 2012 y1l itibariyle 11,5 milyar $€$ GSYİH'ye ve 30 bin $€$ kişi başına gelire sahiptir.

Bölge ekonomisinde hizmet, imalat ve inşaat sektörleri egemendir. Yaşam bilimleri (J\&J Vistakon, Stryker, Roche), bilişim teknolojileri (Intel, Dell, Analog) ve finansal hizmetler (GE Capital, Northern Trust, Genworth) gibi alanlarda 108 tane Çok Uluslu Şirket vardır. Bu şirketler, bölgede yaklaşık 13 bin kişiyi istihdam etmiştir (SA, 2012: 40).

Shannon Kalkınma Ajansı, yerel kalkınmayı hızlandırmak üzere teknoparklar kurmuştur. Bunlardan ilki, 1984 yılında kurulan Ulusal Teknoloji Parkı'dır (NTP). Daha sonra kurduğu teknoparkları, Bilgi Ağı (SDKN) bünyesinde birbirine bağlamıştır.

\footnotetext{
12 Yönetişim, kamu ve özel kesim aktörlerinin işbirlıği yapmasıdır. Putnam, E-R'nin kalkınmasında ekonomik, sosyal ve yönetim unsurlarının önemini vurgulamış; (Pfleger, 2004: 4); bölgedeki aracılık kültürünün, demokratik kültürün bir ürünü olduğunu belirtmiştir (Amin, 1999: 397).
} 
Bu bölümde Shannon Kalkınma Ajansı ile onun kurduğu Ulusal Teknoloji Parkı ve Bilgi Ağ 1 ele alınmıştır.

\subsection{Shannon Kalkınma Ajansı}

Shannon Kalkınma Ajansı (SD), yerel kalkınmanın bir öncüsü olarak 1959 yılında kurulmuştur. Başlangıçta Shannon Havaalanı'nın yolcu ve yük trafiğini artırmayı; sanayi ve turizm sektörlerini geliştirmeyi amaçlamıştır (Canzanelli ve Dichter, 2001: 41). Günümüzdeki amac1 ise, bölgenin bütüncül (entegre) bir şekilde büyümesini ve bilgi toplumuna dönüşmesini sağlamaktır (Kayasü et al., 2003: 50).

Yönetimi, ilgili bakanlıklar tarafından atanmıştır. Ajansta 267 kişi istihdam edilmiştir (SD, 2010: 24). Faaliyetlerini, yönetişim yaklaşımı ile yürütmüştür (LCDB, 2001: 45; Rees et al., 2006: 13). Mali kaynakları, hizmet gelirleri ve AB fonlarıdır (Kayasü et al., 2003: 53-54).

Faaliyetleri, yerel yönetim reformu ile 2012 yılında sınırlandırılmıştır. Shannon Serbest Bölgesi'nin (SFZ) yakınındaki gayrimenkullerden sorumlu olmuş; adı, Shannon Ticari Girişimler Limited olarak değiştirilmiştir (MWRA, 2012: 29).

Yerel kalkınmada, yenilik, girişimcilik, işbirliği, ağlar ve çevresel sürdürülebilirlik ilkelerini benimsemiştir (SD, 2010: 2). Başlıca faaliyetleri şunlardır (OECD: 2; Kayasü et al., 2003: 50):

- Shannon Serbest Bölgesi (SFZ, 1960) ile bölgeye sanayi yatırımlarını çekmek.

- Shannon Dünya Havacılık Parkı ile havacılık sektörünü desteklemek.

- Ulusal Teknoloji Parkı (NTP, 1984) ile ileri teknolojiyi ve Ar-Ge'yi teşvik etmek.

- Ar-Ge kurumlarını birbirine bağlamak için Bilgi Ağı'nı (SKDN, 2001) kurmak.

\subsection{Ulusal Teknoloji Parkı}

Shannon bölgesinin kalkınmasını yönlendiren başlıca iki kurum, Shannon Kalkınma Ajansı (SD) ve Ulusal Teknoloji Parkı'dır (NTP). NTP, yaklaşık 20 bin kişinin istihdam edildiği 55 tane teknoparkı yöneten SD’nin kurduğu ilk teknoparktır. Shannon Kalkınma Ajansı ile Limerick Üniversitesi (UL) iş birliğinde 1984 yılında kurulan ve yönetilen NTP, yerel kalkınmada iki aktörün nasıl sinerji yarattığına güzel bir örnektir (Boucher et al., 2003: 893). Ülkenin ilk bilim ve teknoloji parkıdır. Yeni teknolojiye ve bilgiye dayalı firmaları desteklemek için kurulmuştur. Başlıca faaliyeti, Limerick Üniversitesi'nin eğitim ve Ar-Ge gibi imkanlarını firmalara sunmaktır (Charles, 2006: 125).

Shannon Kalkınma Ajansı ve Limerick Üniversitesi, bilişim alanı mezunlarını istihdam ederek bölge dışına göç etmesini önlemek istemiştir. Bu amaçla bölgenin bilgi toplumu ve yenilik sistemi altyapısını geliştirerek bilişim kümesini desteklemiştir. Bu stratejinin örnekleri, Limerick Üniversitesi bünyesinde NTP'nin ve Shannon Soft'un (yazılım kümesi, 1997) kurulmasıdır (Boucher, 2000: 56).

2009 y1lı itibariyle Limerick Üniversitesi'nden mezun olanların \% 38'i Shannon Bölgesi'nde (Mid-West) istihdam edilmiştir. Bunu sırasıyla Doğu (\% 29) ve Güney Batı (\% 14) bölgeleri izlemiştir. Mezunlar daha ziyade firma-finans-sigorta (\% 29), eğitim (\% 24) ve sağlik (\% 15) alanlarında iş bulmuştur (Buckley, 2011: 126-127).

NTP, bilişim teknolojileri gibi önemli sektörlerde Üniversite-Sanayi İşbirliği’ni geliştirmiştir. Yenilik Çalışmaları (IW) ile kuluçka hizmeti vermiştir (Parker, 2007: 16-17). Shannon Kalkınma Ajansı ve Yenilik Çalışmaları, NTP'de Limerick Üniversitesi ile iş birliği yapan yeni (start-up) firmaları desteklemiştir. Bölgedeki çok sayıdaki firma, IW'de kurulmuştur (OECD: 7, 16). 
Limerick Üniversitesi’nin araștırma programlarının geniș kapsamlısı, spin-off firmalara hizmet veren Yenilik Merkezi'dir (IC $\left.{ }^{13}\right)$. Shannon Kalkınma Ajansı'nın NTP bünyesinde 1980 yılında kurduğu Yenilik Merkezi, yeni ve ihracat odaklı firmalara kuluçka hizmeti vermiştir (Boucher, 2000: 34; Roper et al., 2002: 8). Yeniliklerin Kampüs Girişim Programı ile de Limerick Üniversitesi’ndeki girişimcilerin yeni, teknoloji ve bilgi yoğun firmalar kurmasını desteklemiştir (LCDB, 2001: 47).

Shannon Kalkınma Ajansı, NTP için yeni gelişme alanları belirlemiştir. Bunlar, dijital sanayi, biyo-mühendislik, tıbbi cihazlar, yazılım ve yüksek potansiyelli başlangıç kuruluşlarıdır (HPSUs). HPSU'lar, teknolojik yeniliklere dayalı firmalardır. İhracat potansiyeli yüksek bilgiye dayalı ürün veya hizmetler üretmektedir (OECD: 4-6). Shannon Kalkınma Ajansı'nın desteğiyle bölgeye yatırım, istihdam ve Ar-Ge bakımından katkı sağlamışlar. Mesela 2005 yılında kurulan 38 firmadan 21 tanesi HPSU'lar olup; bunlar, 5 milyon $€$ 'dan fazla Ar-Ge harcaması yapmışlar (SD, 2005: 8-9).

NTP'nin gelişiminde birçok unsur etkili olmuştur. Bunlar, Ar-Ge, eğitim ve yetişmiş işgücüdür (Boucher, 2000: 31). Parkta, bilişim teknolojileri alanındaki Çok Uluslu Şirketler, Yenilik Çalışmaları ve Ar-Ge kurumları olmak üzere 5 bin nitelikli işgücünü istihdam eden 80'den fazla kuruluş yer almıştır. Yerli ve yabancı firmaların kümelendiği NTP'de, bilişim teknolojileri, materyaller ve e-business sektörleri öne çıkmıştır (Parker, 2008: 839, 845).

NTP'deki Çok Uluslu Şirketlere örnek olarak Vistakon ve Cool Medical gösterilebilir. Jhonson \& Jhonson firmasının bir iştiraki olan Vistakon, NTP'de 1996 yılında bir tesis kurmuştur. Yaklaşık 1.000 kişinin çalıştığı bu tesis, Vistakon'un ABD dışındaki tek tesisi olup; dünyanın en büyük kontakt lens üretim birimlerinden biridir. Cool Medical ise, dünyada özel sektöre ait en büyük tıbbi cihazlar üreticisidir. Bu firmanın da NTP'de 800'den fazla kişinin istihdam edildiği bir tesisi vardır (Çelik ve Yıldız, 2015: 543).

Kısaca, Shannon Kalkınma Ajansı, Limerick Üniversitesi, Ulusal Teknoloji Parkı ve Yenilik Merkezi, Shannon Bölgesel Yenilik Sistemi'nin kurumsal altyapısını oluşturmuştur (Andreosso-O'Callaghan, 2000: 83). Shannon Kalkınma Ajans1, yerel kalkınmada NTP Modeli'nden kazandığı deneyim ile Limerick dışındaki diğer kentlerde de teknoparklar kurmuştur. Bunlar Kerry Teknoloji Park1, Tipperary Teknoloji Parkı, Ennis Bilgi Çağı Parkı ve Birr Teknoloji Merkezi'dir. Son aşamada, bu teknoparkları birbirine bağlamak için Bilgi Ağı'nı (SDKN, 2001) kurmuştur (SD, 2005: 8-9).

\subsection{Bilgi Ă̆ı}

Shannon Kalkınma Ajansı, bölgenin bilgiye dayalı kalkınmasını hedeflemiştir. Bölgede bilişim teknolojilerinin gelişmesinde önemli katkıları olan Limerick Üniversitesi'nin, Yenilik Merkezi'nin ve Ulusal Teknoloji Parkı'nın kuruluş sürecinde yer almıştır. Bu kurumlar, bilginin yaratılması ve yayılması için kurumsal altyapı sağlamıştır (Parker, 2007: 19).

Shannon Kalkınma Ajansı, 1980’lerin başında firma, üniversite ve yenilik unsurlarını entegre etmek için "bilgi ağı"na ihtiyaç duymuştur. Bu amaçla kurduğu beş teknopark (Ulusal Teknoloji Parkı, Kerry Teknoloji Parkı, Tipperary Teknoloji Parkı, Ennis Bilgi Çağı Parkı ve Birr Teknoloji Merkezi), Bilgi Ağı (SDKN) olarak adlandırılmıştır. SDKN, Ulusal Teknoloji Parkı'nın başarısına dayanarak 2001 yılında kurulmuştur. Amacı, bölgenin bilgi toplumuna dönüşmesine katkıda bulunmaktır. Bilgiye dayalı firmaların kümelenmesini sağlamıştır (OECD: 14-15, 18). Bölgedeki bu gelişme süreci, "öğrenen bölge"nin ortaya çıkış1 ile karakterize edilmiştir (Boucher, 2000: 4).

Bir "ürün” sunmak üzere geliştirilen SDKN modeli, İrlanda bağlamında benzersizdir. Bu ürünler, küresel düzeyde altyapı, iş kuluçkaları, ofis ve eğitim kurumlarıyla işbirliğidir. 4 binden fazla kişiyi istihdam eden SDKN'deki teknoparklar, üç temel unsuru bir araya getirmiştir: İş,

\footnotetext{
${ }^{13}$ IC daha sonra Limerick Yenilik Çalışmaları (IWs) olarak adlandırılmıştır (Parker, 2007: 16).
} 
eğitim ve yenilikler. Her teknoparkta Yenilik Çalışmaları adında bir kuluçka yapılmıştır. Bunlar, özellikle bilgi yoğun işlerin geliştirildiği "akı1lı" binalardır (OECD: 15, 18; OECD, 2004: 58).

Shannon Kalkınma Ajansı'nın kurduğu Bilgi Ağı, Bölgesel Yenilik Sistemi olarak kabul edilir. Andreosso-O'Callaghan (2000), Shannon Kalkınma Ajansı'nın yenilikçilik faaliyetlerini Yerel Yenilik Sistemi olarak nitelendirmiştir (Quinn, 2007: 6).

\section{Sonuç}

Çalışmada, İtalya'nın Emilia-Romagna ve İrlanda'nın Shannon bölgelerinde yerel kalkınmada uygulanan teknopark modeli incelenmiştir. Emilia-Romagna'nın küresel rekabet gücünü artırmak için kurulan ERVET Kalkınma Ajansı (1973), 1970'lerden itibaren teknoparklar (RSC'ler: Reel Hizmet Merkezleri); 1990'larda da bunları birleștirerek ERVET Sistemi'ni kurmuştur. RSC'lerden biri olan Teknoloji Geliştirme Merkezi (ASTER, 1985), Bölgesel Yenilik Stratejisi'ni (PRRIITT, 2002) uygulamıştır. PRRIITT kapsamında bölgenin Ar-Ge altyapısını geliştirmek için yenilik parkları gibi kurumlar; daha sonra da bunları birbirine bağlamak için İleri Teknoloji Ağ $(\mathrm{HTN}, 2007)$ kurulmuştur.

1945 y1lından itibaren transatlantik hava trafiğinde yakıt ikmal noktası olan İrlanda'nın Shannon havaalanı, jet uçaklarının gelişmesiyle önemini kaybetmiştir. Bunun üzerine merkezi yönetim, yerel kalkınmaya öncülük etmesi için 1959 yılında Shannon Kalkınma Ajansı'nı (SD) kurmuştur. SD, yerel kalkınmaya teknoparklar aracılığıyla katkıda bulunmuştur. Limerick Üniversitesi (UL, 1972) ile işbirliğinde bölgenin ilk teknoparkı olan Ulusal Teknoloji Parkı'nı (NTP, 1984) kurmuştur. NTP'den edindiği deneyimi, bölgenin diğer kentlerinde de uygulamıştır. Bu çerçevede Kerry Teknoloji Parkı, Tipperary Teknoloji Park1, Ennis Bilgi Çağı Parkı ve Birr Teknoloji Merkezi'ni; son aşamada ise, bu beş teknoparkı birleştirmek suretiyle Bilgi Ağı'nı (SDKN, 2001) kurmuştur.

Yerel kalkınmada teknopark modelinin Emilia-Romagna ve Shannon bölgeleri örnekleri çerçevesinde analiz edildiği bu çalışma ile yapılan başlıca tespitler şunlardır:

- Teknopark modeli, kümelenme ve yönetişim yaklaşımları temelinde geliştirilmiştir.

- Öncüleri, yerel yönetimler ile Bölgesel Kalkınma Ajansı ve üniversitelerdir.

- Teknoparklar, Üçlü Sarmal Modeli'nin uygulanmasını sağlamıştır.

- Teknoparklar, yerel kalkınmaya yatırım, üretim, istihdam, Ar-Ge, yenilik gibi yönlerden katkıda bulunmuş; Emilia-Romagna ve Shannon bölgelerinin, Avrupa'nın en gelişmiş ve en yenilikçi bölgeleri arasında yer almasında etkili olmuştur.

- Teknoparklar ile Sektörel Yenilik Sistemi (SYS); bunları birbirine bağlamak suretiyle de Bölgesel Yenilik Sistemi (BYS) kurulmuştur.

- Emilia-Romagna ve Shannon bölgelerinin, Cooke, Roper ve Wylie'nin (2001) BYS'nin başlıca özellikleri olarak vurguladığı yönetişim, destekleyici kurumsal yapı, aktif bölge yönetimi gibi unsurlara sahip olduğu gözlenmiştir.

$\mathrm{Bu}$ çalışma kapsamında yapılan tespitlerden hareketle geliştirilen öneriler şunlardır:

- Bölgesel kalkınmada Teknopark Modeli, Türkiye için örnek olabilir.

- Teknopark Modeli'nin başarılı olabilmesi için yerel düzeyde sosyal sermaye, beşeri sermaye gibi unsurlar geliştirilmelidir.

- Teknopark Modeli için tahsis edilen kaynakların, yerel kalkınmaya üretim, istihdam, ArGe, yenilik gibi yönlerden katkısını belirlemek için etki analizleri yapılmalıdır.

- Türkiye'de de Emilian Modeli, SD-UL Modeli gibi bölgeye özgü yerel kalkınma modelleri geliştirilebilir. 


\section{Kaynakça}

Amin, A. (1999). The Emilian Model: Institutional Challenges, European Planning Studies, 4(7): 389-405.

Andreosso-O'Callaghana, B. (2000). Territory, Research and Technology Linkages - Is the Shannon Region a Propitious Local System of Innovation?, Entrepreneurship and Regional Development: An International Journal, 12(1): 69-87.

Asheim, B. T. and Isaksen, A. (1996). Location, Agglomeration and Innovation: Towards Regional Innovation Systems in Norway?, 52 p.

ASTER. Hi-Mech District, 24 p.

ASTER (2011). Emilia-Romagna High Technology, Network: Technopoles, 44 p.

ASTER (2012). The Emilia-Romagna Region-Local Analysis Report, 24 p.

Bandini, V. (2006). An Italian Experience for Innovation Promotion, 4th Workshop Project Network for Production integration between Latina American and The Caribbean SMEs, Costa Rica, 21 p.

Bandini, V. (2008). ASTER Science Techonology Business: The Agency for Industrial Research, Technology Transfer and Innovation of Emilia-Romagna Region, 20 p.

Bardi, A. (2007). Emilia-Romagna After Industrial Districts: Regional Policy Implications, Learning Together for Local Innovation: Promoting Learning Regions, B. Gustavsen, B. Nyhan, R. Ennals (ed.), Luxembourg, 165-174.

Bardi, A. and Bertini, S. (2004). Regional Development and Industrial Clusters in Global Competition, 4. LDWL Congress Transnational Cooperation on Social Regulation, $23 \mathrm{p}$.

Bellini, N. (2000). Real Services': A Re-appraisal, European Planning Studies, 8(6): 711-728.

Bianchi, P. and Labory, S. (2011). Industrial Policy After The Crisis: The Case of The EmiliaRomagna Region in Italy, Policy Studies, 32(4): 429-445.

Bologni, L. (2008). The Regional Innovation Strategy and R\&D Policies in Emilia-Romagna, 53 p.

Bologni, L. (2013). Emilia-Romagna Region Smart Specialization Strategy, 46 p.

Bonaretti, P., Open to Innovation, 3rd PRACE Industrial Seminar, 24 p.

Boucher, G. W. (2000). Unireg Regional Case Study Report The Shannon Region, 74 p.

Boucher, G., Conway, C. and Meer, E. V. D. (2003). Tiers of Engagement by Universities in Their Region's Development, Regional Studies, 37(9): 887-897.

Brusco, S. (1982). The Emilian Model: Productive Decentralisation and Social Integration, Cambridge Journal of Economics, 6(2): 167-184.

Buckley, M. (2011). A Sustainable Regional Economic Growth Strategies for Irland's Mid-West: Targets and Policies, Master Thesis in University of Limerick, 245 p.

Camagni, R. and Capello, R. (2012). Regional Innovation Patterns and the EU Regional Policy Reform: Towards Smart Innovation Policies, 52. ERSA Conference in Bratislava, 25 p.

Canzanelli, G. and Dichter, G. (2001). Local Economic Development, Human Development, and Decent Work, $65 \mathrm{p}$.

Capecchi, V. (1992). A History of Flexible Specialisation and Industrial Districts in EmiliaRomagna, in Industrial Districts and Inter-firm Co-operation in Italy, Ed.: F. Pyke, 0. Becattini and W. Sengenberger, 20-36. 
Charles, D. (2006). Universities as Key Knowledge Infrastructures in Regional Innovation Systems, The European Journal of Social Science Research, 19(1): 117-130.

Clara, M. (1999). CITER Info Centre - Knitwear and Textile, Italy Programme for SME Development, UNIDO, $16 \mathrm{p}$.

Clara, M. (2000). Real Service Centres in Italian Industrial Districts Lessons Learned From A Comparative Analysis, UNIDO, 23 p.

Cocchi, A. (2011). Business Models as Systemic Instruments for The Evolution of Traditional Districts?, $41 \mathrm{p}$.

Cooke, P. (1996). Building a Twenty-first Century Regional Economy in Emilia-Romagna, European Planning Studies, 4(1): 53-62.

Cooke, P. (2001). From Technopoles to Regional Innovation Systems: The Evolution of Localised Technology Development Policy, Canadian Journal of Regional Science, (24): 2140.

Cooke, P. (2004), The Role of Research in Regional Innovation Systems: New Models Meeting Knowledge Economy Demands, International Journal of Technology Management, (28): 507533.

Cooke, P. and Memedovic, O. (2003). Strategies for Regional Innovation Systems: Learning Transfer and Applications, UNIDO World Industrial Development Report, 25.

CUP (Central Europe Programme) (2010). Free: From Reseach to Enterprise-Innovation Systems Guidebook, 48 p.

Çelik, F. (2015). Bölgesel Kalkınma Ajanslarının Yeniliklere Katkıları: Teori, Deneyimler ve Türkiye Uygulamalarının Değerlendirilmesi, Erciyes Üniversitesi Sosyal Bilimler Enstitüsü, Doktora Tezi, Kayseri.

Çelik, F. (2018). Shannon Kalkınma Ajansı'nın (İlanda) Yenilikçilik Faaliyetleri, Ankara Üniversitesi Sosyal Bilimler Dergisi, 9(2): 14-36.

Çelik, F. (2019a). Yerel Kalkınmada Üniversite-Kalkınma Ajansı İşbirliği: Türkiye (İzmir) Örneği, Karabük Üniversitesi Sosyal Bilimler Enstitüsü Dergisi, 9(1): 41-62.

Çelik, F. (2019b). Styria Kalkınma Ajansı'nın (SFG) Yenilikçilik Faaliyetleri, Ankara Üniversitesi Siyasal Bilgiler Fakültesi Dergisi, 74(3): 875-893.

Çelik, F. (2019c). Emilia-Romagna Bölgesi'ne (İtalya) Özgü Ekonomik Kalkınma Modeli: Emilian Modeli, Ankara Üniversitesi Sosyal Bilimler Dergisi, 10(2): 45-55.

Çelik, F. (2019d). Emilia-Romagna Bölgesi (İtalya) Yenilik Stratejisi'nin (PRRIITT) Değerlendirilmesi, Sosyal Ekonomik Araştırmalar Dergisi, 19(37): 1-25.

Çelik, F. ve Yıldız, R. (2015). Yerel Kalkınma Sorunu ve Bunun Çözümünde Üniversitelerin Rolü: Shannon Kalkınma Ajansı (SD) ve Limerick Üniversitesi (UL) Örneği, 3. Uluslararası Bölgesel Kalkınma Konferansı, Bingöl, 532-548.

Dura, C. (1994). Üniversite-Sanayi İşbirliği Üzerine Bir Deneme, Ankara Üniversitesi Siyasal Bilgiler Fakültesi Dergisi, 49(3): 101-117.

EC (European Commission) (2011). Regional Innovation Monitor (2010 Annual Report), 97 p.

EC (2013). Summary Assessment of Emilia-Romagna (ESIC European Service Innovation Centre Report), 43 p.

Ederer, P.,Schuller, P. and Williams, S. (2011). Human Capital Leading Indicators: How Europe's Regions and Cities Can Drive Growth and Foster Social Inclusion, 84 p. 
E-R (Emilia-Romagna) (2005). Regional Report, Bologna, 48 p.

E-R (2007). Building and Improving Support for RTD Policy and Public Spending BIS-RTD, 22 p.

Eraydın, A. (2007). Politikalardan Süreç Tasarımına: Yeni Bölgesel Politikalar ve Yönetişim Modelleri, 2. Bölgesel Kalkınma ve Yönetişim Sempozyumu, İzmir, 5-23.

ERVET. Policies for Enterprises-Italy, 5 p.

ERVET (2008). Guide for Foreign Investment in Emilia-Romagna, 62 p.

Etzkowitz, H. and Leydesdorff, L. (1995). The Triple Helix-University-Industry-Government Relations: A Laboratory for Knowledge-Based Economic Development, EASST Review, (14): 14-19.

EURADA (1999). Creation, Development and Management of RDAs. Does it have to be so difficult?, $169 \mathrm{p}$.

Gagliardi, D., Mina, A. and Cunnigham, P. (2007). Analysis of The Regional Dimensions of Investment in Research Case Study Regional Report: Emilia-Romagna (Italy), 54 p.

Gülbaş, S. Y. (2011). İnovasyon: Teknopark Modeli, ANKEM Dergisi, (25): 139-145.

Hospers, G., Desrochers, P. and Sautet, F. (2009). The Next Silicon Valley? On The Relationship Between Geographical Clustering and Public Policy, International Enterpreneurship and Management Journal, 5(3): 285-299.

Humphrey, J. and Schmitz, H. (1995). Principles for Promoting Clusters \& Networks of SMEs, $34 \mathrm{p}$.

Kayasü, S., Pınarcioğlu, M., Yaşar, S. S. ve Dere, S. (2003). Yerel/Bölgesel Ekonomik Kalkınma ve Rekabet Gücünün Artırılması: Bölgesel Kalkınma Ajansları, İTO Yay., 148.

KB (Kalkınma Bakanlığı). (2012). Kalkınma Ajansları Genel Faaliyet Raporu 2012, 196.

KB. (2013). Kalkınma Ajansları 2013 Y11ı Genel Faaliyet Raporu, 295.

Kiper, M. (2013). Sektörel İnovasyon Sistemi, Biyoteknoloji Sektörel İnovasyon Sistemi içinde (Ed.: Mahmut Kiper), Türkiye Teknoloji Geliştirme Vakfi, 7-30.

Landabaso, M. and Reid, A. (1999). Developing Regional Innovation Strategies: The European Commission as Animateur, in Regional Innovation Strategies. Morgan, K. and Nauwelaers, C. (Ed.) The Stationery Office. Regional Studies Association, 18-38.

LCDB (Limerick County Development Board) (2001). Analysis of Economic, Social \& Cultural Situation Of County Limerick, 132.

López-Estornell, M. (2011). Similar Reality, Confronted Policies: Innovation and Clusters in Emilia-Romagna, Valencia and Veneto, 28.

López-Estornell, M., Barbera-Tomas, D. et al. (2012). Evolution of Innovation Policy in EmiliaRomagna and Valencia: Similar Reality, Similar Results? 30.

Maccani, P. (2007). The Role of a Regional Development Agency in The Improvement of Regional Territorial Policies, Italy-Turkey Bilateral Cooperation Project Izmir, 31.

Manuelli, A. (2002). Enhancing Productivitiy and Competetitiveess of SMEs Through Clustering and Networking: The Experience of Italy, 11.

Marzocchi, C. (2009). The Evolution of An Innovation Policy in A Local System of Production. The Case of the Regional Programme for Industrial Research, Innovation and Technology Transfer, Università Ferrara PhD Thesis, 145. 
Mosconi, F. and Mantovi, A. (2010). The 'Emilian Model' for The Twenty-First Century, 20 p.

MWRA (Mid-West Regional Authority) (2012). Annual Report 2012, 40.

OECD. Shannon Development: Sample Case Studies (50 Years (1959-2009) of Commitment to the Shannon Region), $31 \mathrm{p}$.

OECD (2004). Information Technology Policy Survey, 113.

Oğuztürk, B. S. (2003). Yenilik Kavramı ve Teorik Temelleri, Süleyman Demirel Üniversitesi İktisadi ve İdari Bilimler Fakültesi Dergisi, 8(2): 255-273.

Oğuztürk, B. S. (2006). Yenilikte Sistem Yaklaşımı ve Temel Dinamikleri: Ekonomik Değişim ve Büyüme Temelli Bir Yaklaşım, Süleyman Demirel Üniversitesi İktisadi ve İdari Bilimler Fakültesi Dergisi, 11(1): 121-139.

Özdemir, Y. (2014). Teknolojik İnovasyon Güdümlü ABD Ekonomisindeki Teknoparkların Ülke Kalkınmasindaki Rolü, www.sanayisurasi.gov.tr, 21.

Parker, R. (2007). Networked Governance or Just Networks? Local Governance of the Knowledge Economy in Limerick (Ireland) and Karlskrona (Sweden), 27.

Parker, R. (2008). Governance and The Entrepreneurial; Economy: A Comparative Analysis of Three Regions, Entrepreneurship Theory and Practice, 32(5): 833-854.

Pfleger, D. (2004). Aspect of Emilia Romagna as An Economic Development Model, 17.

Pietrobelli, C. and Rabelloti, R. (2002). Business Development Service Centres in Italy, An Empirical Analysis of Three Regional Experiences: Emilia Romagna, Lombardia and Veneto, United Nations ECLAC, 84.

Porter, M. (2003). The Economic Performance of Regions, Regional Studies, 37(6-7): 549-578.

Quinn, B. (2007). Ireland: The Shannon Experience, 7.

Rees, N., Quinn, B. and Connaughton, B. (2006). Europeanisation, Adaptation and EU Regional Policy in Ireland: Assessing The 'Goodness of Fit, 26.

Roper, S., Hewitt-Dundas, N. and Savage, M. (2002). Benchmarking Innovation Performance in Ireland's Three NUTS 2 Regions, 44 p.

Rinaldi, A. (2002). The Emilian Model Revisted: Twenty Years After, 24.

Serafini, M. (2011). Technology Transfer in Emilia-Romagna Between Institutional Measures and "Informal" Collaborative Relations. The Case of the University of Bologna, 13.

SA (Shannon Airport) (2012). Shannon Development Change Management Tast Force Report, 89.

SD (Shannon Development) (2005). Annual Report 2005, 103.

SD (2010). Annual Report 2010, 58.

Sungur, O. ve Keskin, H. (2009). Coğrafi Yakınlık 'Hala' Önemli mi? Yerel İnovasyon Modellerinden Çok-Yerelli Bilgi Dinamiklerine Dönüşüm, Alanya Iş̧letme Fakültesi Dergisi, l(2): 107-131.

Sungur, O. ve Keskin, H. (2011). Yenilikte Sistem Yaklaşımı ve Bölgesel Yenilik Sistemleri: Kavramlar, Kuramlar, Politikalar, I. Uluslararası Bölgesel Kalkınma Konferansı, Malatya: 161-168.

Tödtling, F. and Trippl M. (2005). One Size Fits All? Towards a Differentiated Regional Innovation Policy Approach, Research Policy, 34: 1203-1219. 
Uyarra, E. (2008). What is Evolutionary About 'Regional Systems of Innovation'? Implications for Regional Policy, Manchester Business School Working Paper, Number 565, 23.

Uyarra, E. and Haarich, S. N. (2002). Evaluation, Foresight and Participation as New Elements For Regional Innovation Policy Practice: Lessons From The Regional Innovation Strategies (RIS). ERSA Conference, Dortmund, 20.

Vecchio, P. D. (2008). Regional Innovation Strategies in Europe A Comparative Study of EmiliaRomagna and Friuli-Venezia-Giulia, 47.

Yalçıntaş, M. (2014). Üniversite-Sanayi-Devlet İşbirliğinin Ülke Ekonomilerine Etkileri: İstanbul Teknopark Örneği, Finansal Araştırmalar ve Çalı̧̧malar Dergisi, 5(10): 83-106.

Yıldırım, A. ve Şimşek, H. (2013). Sosyal Bilimlerde Nitel Araştırma Yöntemleri, Ankara: Seçkin Yayınc1lik, 448. 